\title{
The Effectiveness of Acceptance and Commitment Therapy on Insomnia Patients (A Single-arm Trial Plan)
}

\author{
Insomnia Hastalarında Kabul ve Kararlıık Tedavisinin Etkililiği (Tek-kollu Çalıșma \\ Planı)
}

(D) Ali Zakiei, (D) Habibolah Khazaie

Sleep Disorders Research Center, Health Institute, Kermanshah University of Medical Sciences, Kermanshah, Iran

\begin{abstract}
Objective: Studies focusing on the effects of acceptance and commitment therapy (ACT) on insomnia and sleep components are limited in number. Therefore, it seems that the effects of this therapy method as a new psychological treatment need to be explored in a comprehensive fashion. Accordingly, the current study has been carried out in order to evaluate the effectiveness of ACT on insomnia patients. Materials and Methods: Current study uses a single-arm trial plan where four participants are chosen from among individuals who visited Kermanshah University Faculty of Medicine, Sleep Disorders Research Center, Kermanshah in 2018. Based on the results from polysomnography and psychological interviews, insomnia of the participants has been confirmed. Individual participants attended eight sessions of ACT.

Results: The results show variance in the scores for variables of "experiential avoidance", "dysfunctional beliefs and attitudes about sleep", "acceptance of sleep difficulties", and "sleep quality" for all four participants after the ACT sessions were completed. Moreover the results of the study show that the level of total sleep for all four participants increased. This means that ACT had a significant impact on increasing the sleep duration. With regards to other sleep-related variables, the variance trend after the therapy was significant.

Conclusion: Based on the results of the study, it can be said that ACT improves sleep quality of insomnia patients. Therefore, therapists are recommended to utilize this therapeutic method in order to mitigate the problems of insomnia patients.
\end{abstract}

Keywords: Insomnia, sleep quality, acceptance and commitment therapy
Öz

Amaç: Insomni ve uyku komponentlerinde kabul ve kararlılık tedavisinin (ACT) etkilerine odaklanan çalışma sayısı sınırlıdır. Dolayısıyla, yeni bir psikolojik tedavi olarak, bu tedavi metodunun etkilerinin ayrıntılı bir şekilde araştırılması gereklidir. Bundan dolayı, insomnia hastalarında $A C T^{\prime}$ nin etkililiğini değerlendirmek üzere bu çalışma yürütülmüştür.

Gereç ve Yöntem: Tek kollu çalışma planı kullanılan çalışmada, dört katılımcı, 2018 yılında Kermeanshah Üniversitesi Tıp Fakültesi, Uyku Bozuklukları Merkezi'ni ziyaret eden kişiler arasından seçilmiştir. Polisomnografi ve psikolojik görüşmelerde elde edilen verilere dayanılarak hastaların insomni tanısı doğrulanmıştır. Her katılımcı sekiz ACT oturumuna katılmıştır.

Bulgular: ACT oturumları tamamlandıktan sonra, dört katılımcıdan elde edilen sonuçlarda, "deneyimsel kaçınma", "uyku ile ilgili işlevsiz inanç ve tutumlar" "uyuma güçlüklerinin kabullenilmesi" ve "uyku kalitesi" değişkenlerinin skorlarında farklılık saptanmıştır. Ayrıca, çalışmanın sonuçları her dört katılımcı için de toplam uyku süresinin artığını gösterir. Bu durum, uyku süresinin artmasında ACT'nin anlamlı bir etkisi olduğu anlamına gelir. Diğer uyku ile ilişkili değişkenler için de, tedavi sonrasındaki değişiklik eğilimi anlamlı olmuştur.

Sonuç: Çalışma sonuçlarına dayanarak, $\mathrm{ACT}^{\prime}$ nin insomni hastalarında uyku kalitesini iyileştirdiği söylenebilir. Bu nedenle, terapistlerin insomni hastalarının sorunlarını azaltmak için bu tedavi yöntemini kullanmaları önerilir.

Anahtar Kelimeler: Insomnia, uyku kalitesi, kabul ve kararlılık tedavisi

\section{Introduction}

Insomnia has a number of adverse effects on quality of life (1). It can be a risk factor for diseases such as diabetes and cardiovascular diseases $(2,3)$. Moreover, the results of a meta- analysis show that insomnia is a predictor for the development of mental disorders such as depression, anxiety, and alcohol abuse (4). Therefore, it is essential to better explore this disorder and search for an appropriate treatment for it. For years,

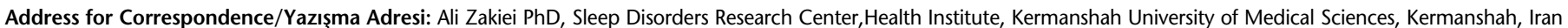
Phone: +98 9187190274 E-mail: zakieiali@gmail.com ORCID-ID: orcid.org/0000-0002-5259-6104 Received/Geliş Tarihi: 29.05.2019 Accepted/Kabul Tarihi: 12.08.2019

${ }^{\odot}$ Copyright 2018 by Turkish Sleep Medicine Society / Journal of Turkish Sleep Medicine published by Galenos Publishing House. 
cognitive-behavioral therapy (CBT) has been used for treating insomnia. However, the results of a meta-analysis show that the effect size of CBT on insomnia is moderate, which is lower than the effect size of CBT on other mental disorders (5).

An alternative treatment can be acceptance and commitment therapy (ACT). ACT aims to improve psychological flexibility through six processes or skills, with the ultimate aim of increasing effective or meaningful action. The ACT processes include: acceptance, defusion, contact with the present moment, selfas-context, values, and committed action (6). Ultimately, ACT increases psychological flexibility (7). Psychological flexibility refers to the ability for adaptive behavior based on values despite having distressing experiences (8). Psychological flexibility has a positive impact on mental health (9). In fact, psychological flexibility is the core treatment target in ACT (10). Various studies have focused on the effects of ACT on mental disorders; the results of a meta-analysis have shown that ACT impacts anxiety (11); the results of another study show that ACT is a promising treatment for depression (12). Moreover, the results of other studies indicate the effectiveness of this type of therapy for disorders such as post-traumatic stress disorder (13), and substance use disorders (14).

However, in the field of insomnia, there are a very limited number of researchers who focused on ACT and its components. Some studies have only explored some aspects of this model. For instance, the results of previous research show that mindfulnessbased interventions can improve sleep quality (15). Some others have considered this topic in a purely descriptive manner. For example, McCracken et al. (16) predicted insomnia and sleep difficulties based on psychological flexibility. Their results show that acceptance (experiential avoidance) is related to the intensity of insomnia and sleep difficulties, and mindfulness is associated with the intensity of insomnia. Moreover, the results of this study show that variables including acceptance, mindfulness, and value-based actions (psychological flexibility) can predict insomnia. However, the important point is to explore the effects of this therapy on components related to insomnia such as the beliefs of the patient since the majority of studies focusing on the role of cognitive factors on insomnia have emphasized the role of cognitions before sleep and nighttime cognitions related to sleep (17). Previous research shows that compared to people with normal sleep patterns, insomnia patients have a larger number of negative thoughts during the nighttime waking periods (18). It is believed that people suffering from insomnia are also suffering from automatic negative thoughts and uncontrollable anxiety (19). Therefore, in order to treat insomnia, these variables must be considered. On the other hand, studies on the effects of this type of therapy on treating insomnia and sleep components are very limited in number. Thus, it is believed that the effects of ACT as a novel psychological treatment must be explored. Therefore, the current study has been carried out in order to evaluate the effectiveness of ACT on sleep quality, sleep-related variables, and dysfunctional beliefs and attitudes about sleep in patients suffering from insomnia.

\section{Materials and Methods}

\section{Study Design}

The current study is based on single-arm trial methodology which utilizes a non-concurrent multiple baseline design.

\section{Sample and Sampling Method}

Among the individuals visiting the Kermanshah University Faculty of Medicine, Sleep Disorders Research Center, Kermanshah, Iran in 2018, four participants were selected. Based on the results extracted from polysomnography and interviews with the psychotherapists, the fact that these participants were suffering from insomnia was confirmed. During the course of their treatment for insomnia, the participants had taken a number of medicines, but they were still suffering from this disorder. It was explained to them that they could stop taking the drugs and start psychotherapy and participate in the study. The criteria for entering the study included complete consent for participating in the study, the participants had to be between 18 and 60 years old, the participants had to have at least nine years of education, and the participants must not be suffering from chronic physical illnesses such as diabetes, cardiovascular diseases, pulmonary diseases, and diseases related to thyroid glands (1-4). The criteria for eliminating the participants from the study included suffering from other sleep disorders, being under simultaneous treatment with other therapies, suffering from chronic mental disorders, particularly personality disorders, and being addicted to any illicit drugs (1-4).

In order to abide by the ethical rules of research, the participants were informed that they can exit the study in case they have any problems with the participation. After providing informed consent and receiving the necessary guarantees on the confidentiality of the information they provide, the selected sample participated in the study. It is worth mentioning that the current study has been registered in the Kermanshah University Faculty of Medicine, Sleep Disorders Research Center, Kermanshah, Iran and has received an ethical permit from the Ethics Committee of Kermanshah University of Medical Sciences.

\section{Data Collection Tools}

\section{Sleep Diary Table}

Through filling the sleep diary table at least two weeks before the commencement of the therapy session, a report of the patient's sleep pattern is obtained. The results of this diary table provide the sleep pattern for each patient during each night. The time of going to bed, delays in sleep initiation, nighttime sleep duration, and the final time of waking up and getting out of the bed can be obtained from this table for each day. Moreover, the sleep diary table provides some information about sleep quality and the extent of feeling rested. This table is the main tool in the CBT of insomnia and provides useful information for measuring and evaluating insomnia. The table includes eleven questions and it is completed daily by the patient (20). 


\section{Experiential Avoidance Questionnaire (EAQ)}

This questionnaire was developed by Hayes et al. (21) Its original version included 32 items scored based on a 7-point Likert scale. Later versions included 16 and 9 items; however, the final version of this questionnaire contains 10 items, scored on a 7-point Likert scale (which is the version used in the current study). In a study, a single-factor structure was reported for this scale; its Cronbach's Alpha coefficient has been calculated as 0.84 in 2012, the reliability of this questionnaire was evaluated in Iran, providing a Cronbach's Alpha coefficient of 0.82 . In order to evaluate the reliability of this questionnaire, tools such as Beck's Anxiety Scale, Beck's Depression Scale, and Difficulties in Emotion Regulation Scale has been used, providing correlation coefficients of $0.44,0.59$, and 0.59 , respectively. The results of the factor analysis show that the factors have a suitable weight (22).

\section{Dysfunctional Beliefs and Attitudes about Sleep (DBAS)}

This scale, developed by Morin in 1993, includes 10 items related to dysfunctional beliefs and attitudes before sleep which are believed to play a role in the continuation of sleep difficulties. The participants have to mark the level of their agreement with each item on a Likert scale from 0 to 10 . Higher scores are related to higher levels of dysfunctional beliefs and attitudes about sleep. The internal consistency of this scale measured using Cronbach's Alpha method by Morin et al. (23) was reported as 0.77 for the clinical population and 0.79 for general populations.

\section{Pittsburgh Sleep Quality Index (PSQI)}

PSQI is a self-report questionnaire developed in 1989 and this questionnaire is a standard scale containing 18 questions, classified into 7 main components. The first component is related to subjective sleep quality, measured by one question (question 9). The second component is related to sleep latency, which is scores by averaging the scores of question 2 and part (a) of question 5. The third component involves sleep duration, measured using a single question (question 4). The fourth component is related to habitual sleep efficiency whose scores is obtained by dividing all the hours of sleep by all the hours an individual is in bed, multiplied by 100 . The fifth component is related to sleep disturbances measured by averaging the scores of question 5. The sixth component is related to use of sleeping medication, measured through a single question (question 6). The seventh component is related to daytime dysfunction, measured by two questions (averaging the scores of questions 7 and 8). The score for each question ranges from 0 to 3 , and the score for each component can at most be equal to 3 . The sum of the scores of these seven components gives the total score for the scale, which ranges from 0 to 21 . The higher the obtained score is, the lower the sleep quality will be. Scores higher than 5 indicate poor sleep quality. The reliability of PSQI was measured using Cronbach's Alpha coefficient, giving a value of 0.83 (17).

\section{Sleep Problem Acceptance Questionnaire (SPAQ)}

SPAQ was developed by Bothelius et al. (24) for measuring and quantifying the level of acceptance for the problems caused by insomnia in patients suffering from this disorder. They evaluated the validity and reliability of the questionnaire in a cross-sectional study using exploratory and confirmatory factor analysis methods. In their study, three samples were selected. A sample of 372 people, a sample of 215 people, and a sample of 233 people; i.e. a total of 820 participants were entered into the study. Ultimately, the questionnaire with eight questions was confirmed; the questions are divided into "active engagement" and "willingness" factors. The results obtained by the developers of the questionnaire show that accepting sleep difficulties has a significant correlation with variables of intensity of insomnia, experiential avoidance, sleep latency, time of waking up after sleep, dysfunctional beliefs and attitudes about sleep, and sleep-related behaviors.

\section{Treatment Protocol}

ACT sessions will be provided based on the protocol proposed by Lindsay Fletcher, based on the pattern depicted in Table 1.

\section{Procedures}

Before starting the intervention, a pretest was administered to determine the baseline. The participants completed the sleep diary table for a week and the status of patients with regards to selected variables was evaluated. Then, the patients

\begin{tabular}{|l|l|}
\hline Table 1. Acceptance and commitment therapy protocol for insomnia \\
\hline Session & Specification \\
\hline Session one & $\begin{array}{l}\text { Reviewing sleep pattern, expressing the philosophy of the therapy, the metaphor of dirt and glasses, acquiring } \\
\text { commitment, evaluation, understanding the therapy (metaphor of two mountains), creative despair } \\
\text { (metaphor of the hole), mindfulness (breathing exercise), homework }\end{array}$ \\
\hline Session two & $\begin{array}{l}\text { Exercising mindfulness (reconstructing inability to fall asleep), reviewing the sleep pattern, continuing creative despair, } \\
\text { metaphor of fighting the monster, homework assignment }\end{array}$ \\
\hline Sessions three and four & $\begin{array}{l}\text { Evaluating the process of acceptance, exercising mindfulness, explaining willingness, metaphor of passengers on a bus, } \\
\text { distinguishing clean and unclean pain, willingness and acceptance (metaphor of the scale), homework }\end{array}$ \\
\hline Sessions five and six & $\begin{array}{l}\text { Reviewing sleep pattern and exercising mindfulness, introducing and explaining the concepts of self-context and } \\
\text { cognitive dissonance (metaphor of chessboard and lion exercise) } \\
\text { Exercising mindfulness (thoughts and emotions on paper), homework }\end{array}$ \\
\hline Sessions seven and eight & $\begin{array}{l}\text { Reviewing sleep pattern and exercising mindfulness, explaining values, focusing on commitment, metaphor of } \\
\text { uninvited guest, mindfulness by focusing on value and commitment (light, darkness, emotion), homework }\end{array}$ \\
\hline
\end{tabular}


were individually entered into the therapy program; they would complete the sleep diary table each day after waking up and would submit the tables to the therapist at the end of each week. The therapy lasted for eight sessions. One week after the intervention was completed, the experiential avoidance, dysfunctional beliefs and attitudes about sleep, sleep quality, and acceptance of sleep difficulties questionnaires were administered to the participants as a posttest. Three months after the intervention, the patients were contacted and invited to participate in the follow-up stage at the center for sleep disorders.

\section{Statistical Analysis}

In order to analyze the obtained data and test the hypotheses based on the research design, descriptive statistical tests such as mean and standard deviation, and visual analysis methods were used. In order to evaluate the effectiveness of the intervention, the reliable change index, the recovery percentage, and the effect size were used. The data analysis and chart plotting were done in MATLAB software application.

\section{Results}

Table 2 provides the descriptive data for individual participants. As can be seen from Table 2, the first participant is a 43-yearold man who has been suffering from insomnia for eight years; the second participant is a 31-year-old woman with six years of insomnia; the third participant is a 29-year-old man with 10 years of insomnia; and the fourth participant is a 51-year-old woman with 9 years of insomnia.

The participants completed the sleep diary table on a daily basis for eight weeks. The obtained results are presented in Table 3 for each week.

The results in Table 3 show that the sleep duration for the first participant increased from an average of 4.71 hours on the day before the therapy to 5.35 hours on the day after the therapy; the percentage of improvement in this variable for the first participant was 13.59 percent. The sleep duration for the second participant increased from an average of 4.857 hours on the day before the therapy to 7.14 hours on the day after the therapy; the percentage of improvement in this variable for the first participant was $\mathbf{4 7 . 1 2}$ percent. The sleep duration for the third participant increased from an average of 4.857 hours on the day before the therapy to 5.45 hours on the day after the therapy; the percentage of improvement in this variable for the first participant was 47.01 percent. The sleep duration for the fourth participant increased from an average of 2.28 hours on the day before the therapy to 6.20 hours on the day after the therapy; the percentage of improvement in this variable for the first participant was 100 percent. In general, the sleep duration of the participants shows an increasing trend. With regards to the variable of sleep latency, three participants show improvement; however, the third participant didn't show any improvement for this variable. With regards to the variable of number of times waking up during sleep, a decreasing trend is seen for all four participants; in general, the percentage of improvement for the number of times waking up during sleep is 27.47 percent. For variables of subject quality and sleep efficiency, there is an increasing trend for all four participants; the values of for these two variables are higher than 0.8 for all four participants, indicating a significant effect size for the impact of the intervention on these variables. Figure 1 depicts the visual analysis of the data obtained from the intervention for the sleep diary variables.

The variables of experiential avoidance, dysfunctional beliefs and attitudes about sleep, sleep quality, and acceptance of sleep difficulties were measured at three stages (i.e. pretest, posttest, and follow-up), and the results are presented in Table 4.
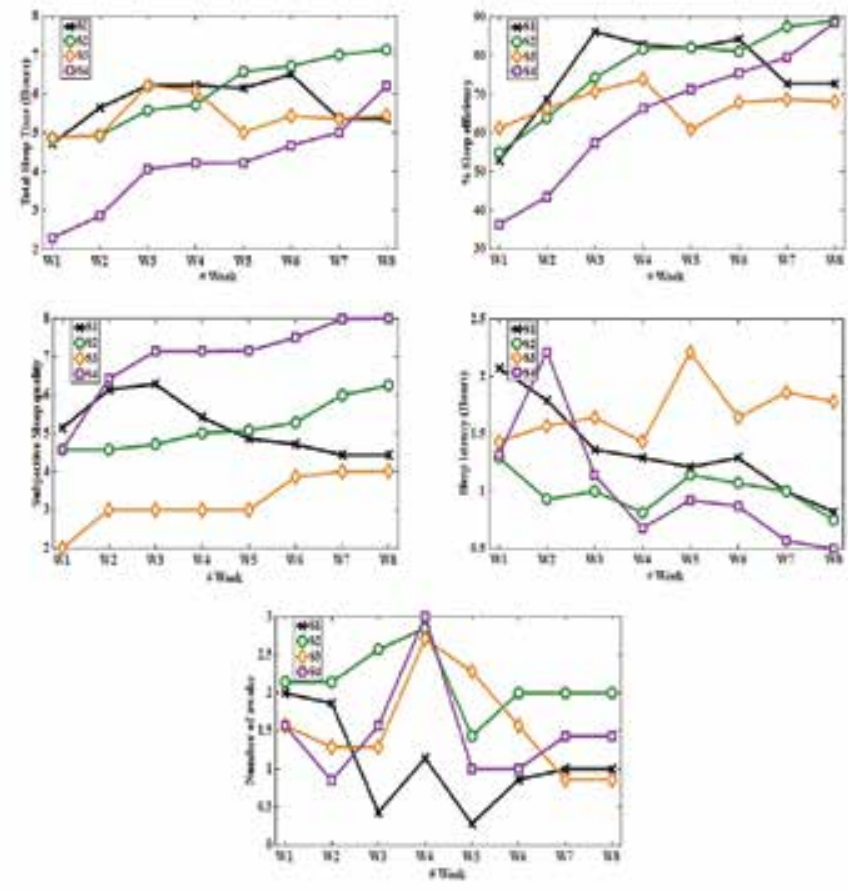

Figure 1. Trend of sleep diary variables during the intervention

\begin{tabular}{|l|l|l|l|l|l|l|}
\hline Table 2. Descriptive data for individual participants & Age & Education & Marital state & Job & Duration of disease \\
\hline Subject & Sex & & & & & \\
\hline S1 & Male & 43 & Bachelor & Marital & Teacher & 8 \\
\hline S2 & Female & 31 & Diploma & Marital & Housewife & 6 \\
\hline S3 & Male & 29 & Master's degree & Single & Unemployed & 10 \\
\hline S4 & Female & 51 & Diploma & Divorced & Unemployed & 9 \\
\hline
\end{tabular}




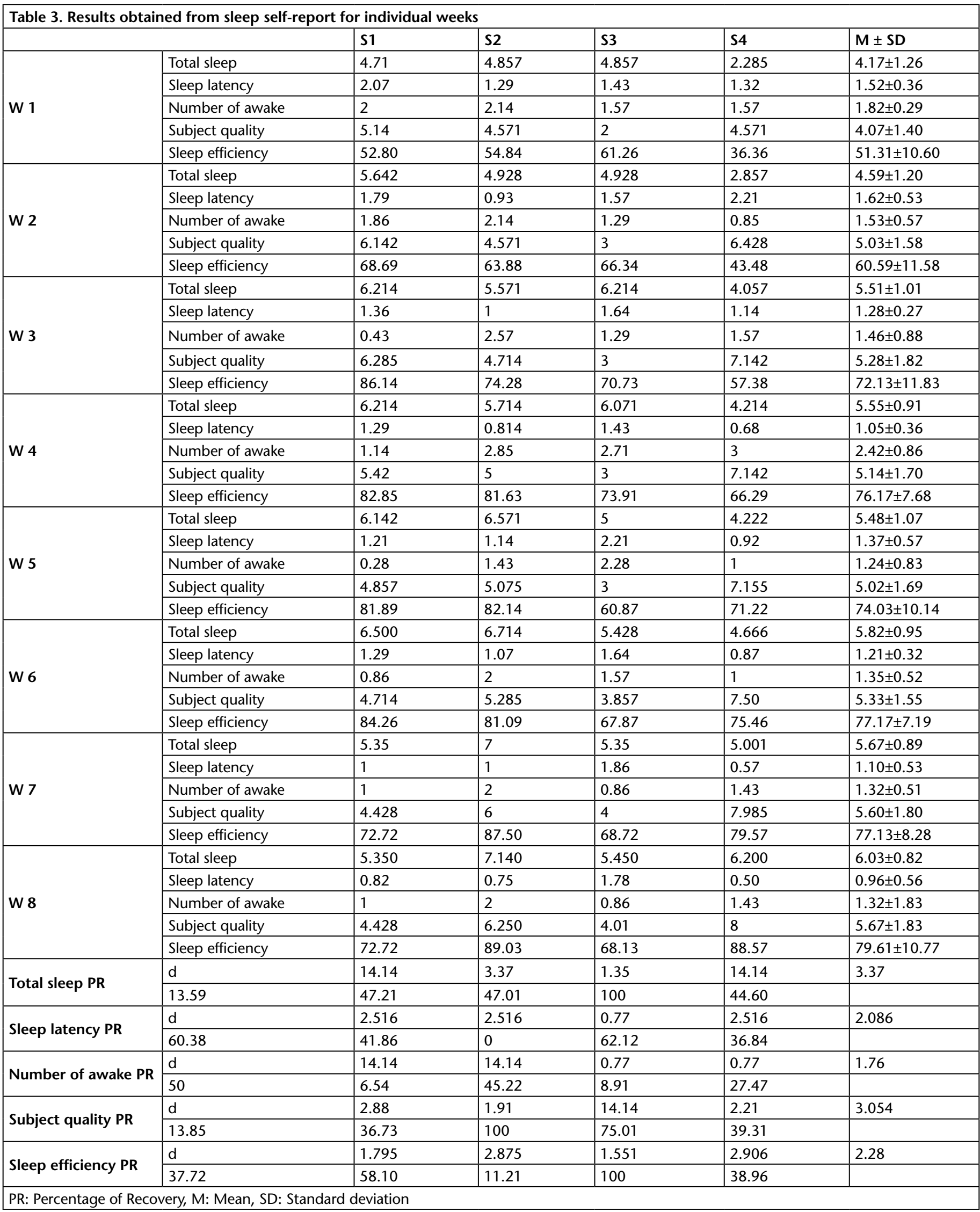




\begin{tabular}{|c|c|c|c|c|c|c|}
\hline & & S1 & S2 & S3 & S4 & $M \pm S D$ \\
\hline \multirow{4}{*}{ Pretest } & Experiential avoidance & 63 & 47 & 41 & 50 & $50.25 \pm 9.28$ \\
\hline & DBAS & 100 & 94 & 91 & 86 & $92.75 \pm 5.85$ \\
\hline & SPA & 11 & 26 & 12 & 23 & $18 \pm 7.61$ \\
\hline & Sleep quality & 16 & 13 & 19 & 16 & $16 \pm 2.44$ \\
\hline \multirow{4}{*}{ Posttest } & Experiential avoidance & 30 & 12 & 28 & 26 & $24 \pm 8.16$ \\
\hline & DBAS & 43 & 24 & 53 & 17 & $34.25 \pm 16.64$ \\
\hline & SPA & 23 & 42 & 35 & 40 & $35 \pm 8.52$ \\
\hline & Sleep quality & 3 & 3 & 11 & 3 & $5 \pm 4$ \\
\hline \multirow{4}{*}{ Follow up } & Experiential avoidance & 28 & 12 & 27 & 17 & $21 \pm 7.78$ \\
\hline & DBAS & 43 & 25 & 50 & 19 & $34.25 \pm 14.63$ \\
\hline & SPA & 25 & 45 & 30 & 46 & $36.50 \pm 10.59$ \\
\hline & Sleep Quality & 3 & 2 & 11 & 4 & $5 \pm 4.08$ \\
\hline \multirow{3}{*}{$\begin{array}{l}\text { Experiential avoidance } \\
\text { PR } \\
\text { d }\end{array}$} & $\mathrm{RCl}$ & 3.148 & 3.062 & 3.174 & 3.423 & 3.214 \\
\hline & 55.55 & 74.46 & 34.14 & 66 & 58.20 & \\
\hline & 1.781 & 1.731 & 1.792 & 1.935 & 1.817 & \\
\hline \multirow{3}{*}{$\begin{array}{l}\text { DBAS } \\
\text { PR } \\
\text { d }\end{array}$} & $\mathrm{RCl}$ & 2.552 & 2.524 & 2.643 & 2.514 & 2.552 \\
\hline & 57 & 73.40 & 45.05 & 77.91 & 63.07 & \\
\hline & 1.732 & 1.719 & 1.794 & 1.706 & 1.732 & \\
\hline $\begin{array}{l}\text { SPA } \\
\text { PR } \\
\text { d }\end{array}$ & $\mathrm{RCl}$ & 2.38 & 2.393 & 1.916 & 2.481 & 2.318 \\
\hline \multirow{5}{*}{$\begin{array}{l}\text { Sleep quality } \\
\text { PR } \\
\text { d }\end{array}$} & 100 & 73.07 & 100 & 100 & 100 & \\
\hline & 1.849 & 1.860 & 1.488 & 1.927 & 1.801 & \\
\hline & $\mathrm{RCl}$ & 2.988 & 3.125 & 2.996 & 2.870 & 2.989 \\
\hline & 81.25 & 84.61 & 42.10 & 75 & 68.75 & \\
\hline & 1.733 & 1.809 & 1.735 & 1.659 & 1.732 & \\
\hline
\end{tabular}

As can be seen from Table 4, the score for "experiential avoidance" has decreased for all four participants. The reliable change index for individual participants shows that ACT has a significant impact on experiential avoidance $(p<0.01)$. The general mean value for the variable of experiential avoidance was 50.25 at the pretest stage, which is decreased to 24 at the posttest stage, further decreasing to 21 at the follow-up stage. The improvement percentage for this variable was 50 percent for three of the participants; it was less than 50 percent for only one of the participants. In general, the improvement percentage for experiential avoidance was 58.20 percent.

The results also indicate that the score of dysfunctional beliefs and attitudes about sleep has decreased for all four participants. The reliable change index for individual participants indicates that ACT had a significant impact on dysfunctional beliefs and attitudes about sleep $(p<0.05)$. The total mean of dysfunctional beliefs and attitudes about sleep at the pretest was 92.75 , which reduced to 34.25 at the posttest stage; it was 34.25 at the follow-up stage as well. The improvement percentage for three participants was higher than 50 percent; it was less than 50 percent for only one participant. In general, the percentage of improvement for this variable was 63.07 percent.

Evaluating the results for the variable of "acceptance of sleep difficulties" shows that the scores for all four participants have increased. Based on the analysis, it can be said that the intervention had a significant impact on acceptance of sleep difficulties $(p<0.05)$. In general, the average score for all four participants at the pretest stage was 18 , increasing to 35 at the post-test stage; this increasing trend has continued at the follow-up stage as well. The percentage of improvement for all four participants was higher than 50 percent. In general, the percentage of improvement was 100 percent.

The results of the analysis show that the score for "sleep quality" reduced for all four participants. The reliable change index for 

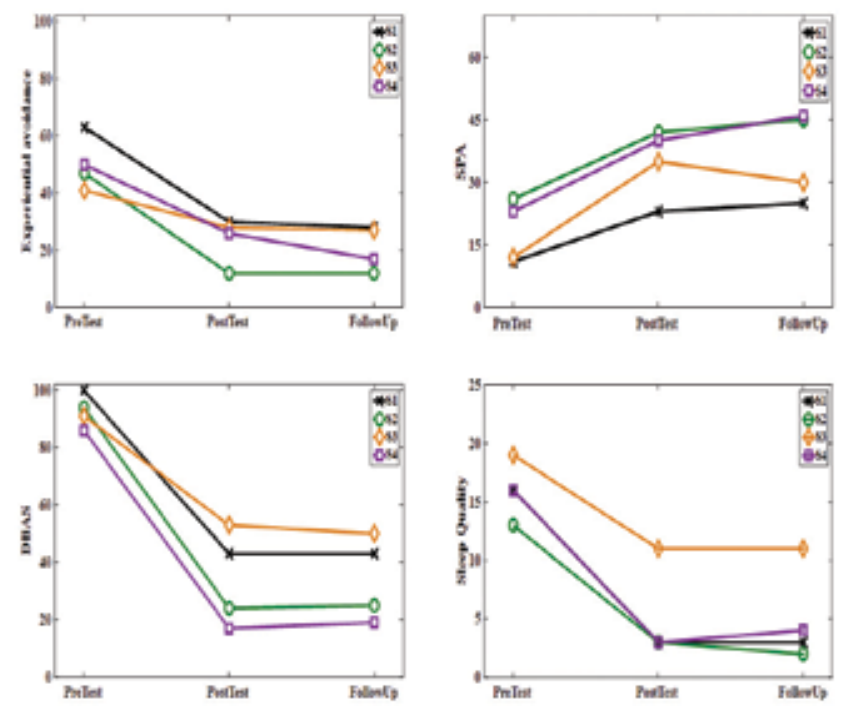

Figure 2. Trend for the variables at three stages of pretest, posttest, and follow-up

individual participants shows that ACT has had a significant impact on sleep quality $(p<0.01)$. The total mean for the variable of sleep quality was 16 at the pretest stage, decreasing to 5 at the posttest stage; it was equal to 5 at the follow-up stage as well. The percentage of improvement for this variable was higher than 50 percent for three of the participant, while it was less than 50 percent for only one of the participants. In general, the percentage of improvement for sleep quality was 68.75 percent. Considering the cutoff point for PSQI, it can be said that the status of participants one, two and four shifted from poor sleeper to good sleeper; the status of participant three remained as poor sleeper. The values reported in Table 4 show that the effect size of the therapy for all the selected variables were high $(\mathrm{d}>0.08)$.

Figure 2 shows the variance trend for the variables at three stages of pretest, posttest, and follow-up.

\section{Discussion}

The results of our study show that the "total sleep" has increased for all four participants, indicating that ACT has a significant impact on increasing sleep duration. Moreover, the results show that sleep latency has decreased for three participants, indicating that ACT was able to reduce sleep latency in three participants. Furthermore, the results of the study show a reduction in the number of times waking up during sleep for the patients after the therapy. The results of the current study also indicate that ACT has a significant impact on subject quality and sleep efficiency; the values of these two variables have increased for all participants.

Reviewing previous research can help explain the results of the current study. The results of a meta-analysis study show that mindfulness, which is a part of ACT, can have a significant impact on components of total waking time and sleep quality; however, it does not have a significant impact on components of sleep latency, total sleep duration, waking up after sleep, sleep efficiency, intensity of insomnia, and dysfunctional beliefs and attitudes about sleep (25). Simister et al. (26) studied the effects of ACT on sleep quality. Their results show that ACT does not have a significant impact on sleep quality. these results are not in line with our results. However, the results of some other studies indicate the effectiveness of ACT on sleep quality and insomnia, which is in line with the results of our study $(27,28)$. Hertenstein et al. (29) studied the effects of ACT on sleep quality of people suffering from preliminary insomnia. The sample of the study included ten participants. The results show that ACT has a significant impact on sleep-related quality of life and the sleep quality of the participants. The effect size in this study for sleep quality was large. Moreover, the results of this study show that the effects of this therapy are longlasting. Furthermore, Daly-Eichenhardt et al. (30) studied the effects of ACT on sleep difficulties. After the completion of the therapy, their results showed a significant change in intensity of insomnia, sleep interference, and sleep efficiency. After a nine-month follow-up their results were reliable. In general, the results of this study indicate the effectiveness of ACT on sleep difficulties of the patients.

Thus, a general rule can be presented: ACT processes can improve the sleep of patients by increasing the willingness of the patients for experiencing poor sleep. In fact, this willingness results in reducing the so-called safety-seeking behavior; some of these behaviors may include effortful attempts to sleep, sleep extension, and activity restriction (16).

The reason behind the effects of ACT on sleep and sleep-related variables is the changes in the attitudes and thoughts of the patients about sleep, which occur during the therapy sessions, as well as the fact that the patients focus on the causes of irrational thoughts, and the vicious cycle of these thoughts. Moreover, during this therapy, by doing exercises based on awareness and creation of despair about past solutions, the patient concludes that previous solutions are not useful and will only intensify insomnia.

Acceptance is an important target in ACT (24). for insomnia patients, acceptance of sleep difficulties is an important step in the process of treatment. In the current study, acceptance of sleep difficulties was measured before commencing the therapy; the results of our study show that ACT affects the level of acceptance of sleep difficulties. Accepting these difficulties can help the patient find their values and have a purposeful life. The results of our study show that ACT can reduce dysfunctional beliefs and attitudes about sleep. In fact, ACT changes the relationship between problematic thoughts and emotions in a way that people stop considering them as symptoms and instead consider them as harmless (31).

The objective of ACT is to increase psychological flexibility, whereby the undesired internal experiences of the patient (e.g. physical symptoms, emotions, and thoughts) become less of an intrusion in the meaningful activities of life (32). This will help insomnia patients to get away from dysfunctional beliefs and attitudes about asleep and create a meaningful 
life for themselves based on the values identified during the treatment process. In a study, McCracken et al. (16) predicted insomnia and sleep difficulties based on psychological flexibility. Their results show that acceptance (experiential avoidance) is associated with the intensity of insomnia and sleep difficulties, and there is a relationship between mindfulness and intensity of insomnia. Moreover, the results of this study show that variables of acceptance, mindfulness, and value-based actions (psychological flexibility) can predict insomnia. The results of another study show that there is a significant correlation coefficient between psychological flexibility and sleep difficulties (33). Therefore, the results of these studies indicate the role of psychological flexibility in predicting sleep quality. The ACT model assumes that symptoms of insomnia will improve through promoting psychological flexibility (8). In fact, psychological flexibility is the core concept in ACT (33). In our study, after the therapy, psychological flexibility has increased among the patients, leading to an improved sleep quality. Therefore, based on the results obtained from the study, it can be said that ACT is effective in treating insomnia. Considering the limited nature of the sample in the current study, we have to be cautious when generalizing the results.

\section{Conclusions}

Based on the results of the study, it can be concluded that ACT improves the sleep quality of patients suffering from insomnia. Moreover, this therapy can help improve acceptance of sleep difficulties by the patients. It can also lead to changes in the dysfunctional beliefs and attitudes about sleep in insomnia patients. In general, it can be argued that ACT is an appropriate treatment method for helping insomnia patients. Therefore, therapists are recommended to utilize this treatment method in order to mitigate the problems and difficulties of insomnia patients.

\section{Acknowledgements}

The authors would like to express their deepest gratitude to the participants for their help in completing the study. Moreover, we would like to thank Iran National Science Foundation and Kermanshah University of Medical Sciences for their financial support for the study.

\section{Ethics}

Ethics Committee Approval: It is worth mentioning that the current study has been registered in the Kermanshah University Faculty of Medicine, Sleep Disorders Research Center, Kermanshah, Iran and has received an ethical permit from the Ethics Committee of Kermanshah University of Medical Sciences.

Informed Consent: The participants were informed that they can exit the study in case they have any problems with the participation

Peer-review: Externally and internally peer-reviewed.

\section{Authorship Contributions}

Concept: H.K., Design: A.Z., Data Collection or Processing: H.K., Analysis or Interpretation: A.Z., Literature Search: H.K., Writing: H.K., A.Z.
Conflicts of Interest: No conflict of interest was declared by the authors.

Financial Disclosure: The authors declared that this study received no financial support.

\section{References}

1. Kyle SD, Morgan K, Espie CA. Insomnia and health-related quality of life. Sleep medicine reviews. 2010;14:69-82.

2. Kawakami N, Takatsuka N, Shimizu H. Sleep disturbance and onset of type 2 diabetes. Diabetes Care 2004;27:282-3.

3. Mallon L, Broman JE, Hetta J. Sleep complaints predict coronary artery disease mortality in males: a 12 year follow up study of a middle aged Swedish population. J Intern Med 2002;251:207-16.

4. Hertenstein E, Feige B, Gmeiner T, Kienzler C, Spiegelhalder K, Johann A, Jansson-Fröjmark M, Palagini L, Rücker G, Riemann D, Baglioni C. Insomnia as a predictor of mental disorders: A systematic review and meta-analysis. Sleep Med Rev 2019;43:96-105.

5. Harvey AG, Tang NK. Cognitive behaviour therapy for primary insomnia: can we rest yet? Sleep Med Rev 2003;7:237-62.

6. Ong CW, Lee EB, Twohig MP. A meta-analysis of dropout rates in acceptance and commitment therapy. Behav Res Ther 2018;104:14-33.

7. Rector NA. Acceptance and commitment therapy: Empirical considerations. Behav Ther 2013;44:213-7.

8. Hayes SC, Luoma JB, Bond FW, Masuda A, Lillis J. Acceptance and commitment therapy: Model, processes and outcomes. Behav Res Ther 2006;44:1-25.

9. Fledderus $M$, Bohlmeijer ET, Smit F, Westerhof GJ. Mental health promotion as a new goal in public mental health care: A randomized controlled trial of an intervention enhancing psychological flexibility. Am J Public Health 2010;100:2372.

10. Wiwe Lipsker C, Kanstrup M, Holmström L, Kemani M, Wicksell RK. The Parent Psychological Flexibility Questionnaire (PPFQ): Item reduction and validation in a clinical sample of Swedish parents of children with chronic pain. Children (Basel) 2016;3:32.

11. Swain J, Hancock K, Hainsworth C, Bowman J. Acceptance and commitment therapy in the treatment of anxiety: a systematic review. Clin Psychol Rev 2013;33:965-78.

12. Folke F, Parling T, Melin L. Acceptance and commitment therapy for depression: A preliminary randomized clinical trial for unemployed on long-term sick leave. Cogn Behav Pract 2012;19:583-94.

13. Twohig MP. Acceptance and commitment therapy for treatmentresistant posttraumatic stress disorder: A case study. Cogn Behav Pract 2009;16:243-52.

14. Lee EB, An W, Levin ME, Twohig MP. An initial meta-analysis of Acceptance and Commitment Therapy for treating substance use disorders. Drug Alcohol Depend 2015;155:1-7.

15. Garland SN, Zhou ES, Gonzalez BD, Rodriguez N. The quest for mindful sleep: a critical synthesis of the impact of mindfulness-based interventions for insomnia. Curr Sleep Med Rep 2016;2:142-51.

16. McCracken LM, Williams JL, Tang NK. Psychological flexibility may reduce insomnia in persons with chronic pain: a preliminary retrospective study. Pain Med 2011;12:904-12.

17. Davoodi I, Neisi A, Khazei H, Arshadi N, Zakiei A. The Roles of Some Cognitive and Emotional Factors in Predicting Insomnia. I Mazandaran Univ Med Sci 2017;27:107-21.

18. Watts FN, Coyle K, East MP. The contribution of worry to insomnia. $\mathrm{Br}$ J Clin Psychol 1994;33:211-20. 
19. Charles M. Insomnia: Psychological assessment and management: Guilford Press; 1993.

20. Edinger JD, Carney CE. Overcoming insomnia: A cognitive-behavioral therapy approach, therapist guide: Oxford University Press; 2014.

21. Hayes SC, Stroshl K, Wilson KG, Bissett R, Pistorello J, Toarmıno D, Polusny MA, Dykstra TEA, Batten SV, Bergan J, Stewart SH, Zvokensky DJ, Eifert GH, Bond FW, Forsyth JP, Karekla M, Mccurry SM. Measuring experiential avoidance: A preliminary test of a working model. The Psychological Record 2004;54:553-78.

22. Abasi E, Fti L, Molodi R, Zarabi H. Psychometric properties of Persian version of acceptance and action questionnaire-II. Journal of Psychological Models and Methods 2013;3:65-80.

23. Morin $C M$, Vallières $A$, Ivers $H$. Dysfunctional beliefs and attitudes about sleep (DBAS): validation of a brief version (DBAS-16). Sleep 2007; 30:1547-54.

24. Bothelius K, Jernelöv S, Fredrikson M, McCracken LM, Kaldo V. Measuring acceptance of sleep difficulties: the development of the sleep problem acceptance questionnaire. Sleep 2015;38:1815-22.

25. Gong H, Ni CX, Liu YZ, Zhang Y, Su WJ, Lian YJ, Peng W, Jiang CL. Mindfulness meditation for insomnia: A meta-analysis of randomized controlled trials. J Psychosom Res 2016;89:1-6.

26. Simister HD, Tkachuk GA, Shay BL, Vincent N, Pear JJ, Skrabek RQ Randomized controlled trial of online acceptance and commitment therapy for fibromyalgia. J Pain 2018;19:741-53.
27. Ong JC, Shapiro SL, Manber R. Mindfulness meditation and cognitive behavioral therapy for insomnia: a naturalistic 12-month follow-up. Explore (NY) 2009;5:30-6.

28. Zhang Jx, Liu Xh, Xie Xh, Zhao D, Shan MS, Zhang XL, Kong XM, Cui $\mathrm{H}$. Mindfulness-based stress reduction for chronic insomnia in adults older than 75 years: a randomized, controlled, single-blind clinical trial. Explore (NY) 2015;11:180-5.

29. Hertenstein E, Thiel N, Lüking M, Külz AK, Schramm E, Baglioni $C$, Spiegelhalder K, Riemann D, Nissen C. Quality of life improvements after acceptance and commitment therapy in nonresponders to cognitive behavioral therapy for primary insomnia. Psychother Psychosom 2014;83:371-3.

30. Daly-Eichenhardt A, Scott W, Howard-Jones M, Nicolaou T, McCracken LM. Changes in sleep problems and psychological flexibility following interdisciplinary acceptance and commitment therapy for chronic pain: an observational cohort study. Front Psychol 2016;7:1326.

31. Harris R. Embracing your demons: An overview of acceptance and commitment therapy. Psychotherapy in Australia 2006;12):70.

32. Feros DL, Lane L, Ciarrochi J, Blackledge JT. Acceptance and Commitment Therapy (ACT) for improving the lives of cancer patients: a preliminary study. Psychooncology 2013;22:459-64.

33. Kato T. Impact of psychological inflexibility on depressive symptoms and sleep difficulty in a Japanese sample. Springerplus 2016;5:712. 